\title{
Does a Computer Science Graduation Requirement Contribute to Increased Enrollment in Advanced Computer Science Coursework?
}

\author{
Steven McGee \\ The Learning Partnership, mcgee@lponline.net \\ Randi McGee-Tekula \\ The Learning Partnership, rmcgee@lponline.net \\ Jennifer Duck \\ The Learning Partnership, jenn@lponline.net \\ Eucilia Dettori \\ DePaul University, lucia@cdm.depaul.edu \\ Part of the Computer Sciences Commons, and the Secondary Education Commons \\ Ronald I Greenbergt \\ LoyolaUniversity Chicago, Rgreen@luc.edu \\ This is a pre-publication author manuscript of the final, published article.
}

\footnotetext{
See next page for addițional authors Recommended Citation

McGee, Steven; McGee-Tekula, Randi; Duck, Jennifer; Dettori, Lucia; Greenberg, Ronald I.; Rasmussen, Andrew M.; Wheeler, Erica; and Shelton, Adam. Does a Computer Science Graduation Requirement Contribute to Increased Enrollment in Advanced Computer Science Coursework?. 2020 Research in Equity and Sustained Participation in Engineering, Computing, and Technology (RESPECT), , : , 2020. Retrieved from Loyola eCommons, Computer Science: Faculty Publications and Other Works,
}

This Article is brought to you for free and open access by the Faculty Publications and Other Works by Department at Loyola eCommons. It has been accepted for inclusion in Computer Science: Faculty Publications and Other Works by an authorized administrator of Loyola eCommons. For more information, please contact ecommons@luc.edu.

(c) 2020 IEEE. Personal use of this material is permitted. Permission from IEEE must be obtained for all other uses, in any current or future media, including reprinting/republishing this material for advertising or promotional purposes, creating new collective works, for resale or redistribution to servers or lists, or reuse of any copyrighted component of this work in other works. 


\section{Authors}

Steven McGee, Randi McGee-Tekula, Jennifer Duck, Lucia Dettori, Ronald I. Greenberg, Andrew M.

Rasmussen, Erica Wheeler, and Adam Shelton 


\section{Does a Computer Science Graduation Requirement Contribute to Increased Enrollment in Advanced Computer Science Coursework?}

\author{
Steven McGee \\ The Learning Partnership \\ Chicago, IL, USA \\ mcgee@lponline.net \\ Ronald I. Greenberg \\ Loyola University Chicago \\ Chicago, IL, USA \\ rig@cs.luc.edu
}

\author{
Randi McGee-Tekula \\ The Learning Partnership \\ Chicago, IL, USA \\ Rmcgee@lponline.net
}

\author{
Jennifer Duck \\ The Learning Partnership \\ Chicago, IL, USA \\ jenn@1ponline.net
}

\author{
Lucia Dettori \\ DePaul University \\ Chicago, IL, USA \\ lucia@cdm.depaul.edu
}

\author{
Andrew M. Rasmussen \\ Chicago Public Schools \\ Chicago, IL, USA \\ arasmussen@cps.edu
}

\author{
Erica Wheeler \\ Chicago Public Schools \\ Chicago, IL, USA \\ ewheeler6@cps.edu
}

\author{
Adam Shelton \\ The Learning Partnership \\ Chicago, IL, USA \\ aqshelton@lponline.net
}

\begin{abstract}
Prior research has shown that students pursuing Exploring Computer Science (ECS) as their first elective course were more likely to pursue another computer science course in high school, as compared to students who took a traditional course as the first course. This study investigated whether the results are consistent when students are pursuing ECS to fulfill the Chicago Public Schools' graduation requirement. ECS is designed to foster deep engagement through equitable inquiry around computer science concepts. It is hypothesized that students who are fulfilling a graduation requirement will pursue additional computer science coursework at rates similar to students who were pursuing ECS as an elective course.

Index Terms-Exploring Computer Science, high school computer science, graduation requirement
\end{abstract}

\section{INTRODUCTION}

A key strategy for broadening CS participation in the Chicago Public Schools (CPS), where a majority of students are Hispanic or African-American, has been the enactment of a high school CS graduation requirement in 2016 [1]. The Exploring Computer Science (ECS) curriculum and professional development (PD) program [2] serves as a core foundation for supporting enactment of this policy. ECS seeks to contribute to broadening the participation of women and minorities and increasing equity in the field of computer science through activities designed to engage students in computer science inquiry around meaningful problems [2]. The genesis of the work that led to the graduation requirement started four years earlier in 2012 with a teacher-led initiative bringing together CPS teachers, CPS administrators, educational researchers, and university faculty. The partnership, which became known as the Chicago Alliance for Equity in Computer Science

This research was supported by National Science Foundation grant numbers CNS-1738572, CNS-1738776, CNS-1738691, CNS-1738515, DRL-1640215, CNS-1542971, and CNS-1543217.

978-1-7281-7172-2/20\$31.00 @2020 IEEE
(CAFÉCS), brought the ECS curriculum and PD program to Chicago [3]. Implementation of ECS in Chicago started out as a voluntary program. It quickly grew to include around 4600 students in the year before the graduation requirement. Almost half of the students who took ECS as an elective class (43\%) went on to take additional high school computer science coursework, compared to one quarter of the students $(26 \%)$ who started with a different computer science class [4].

While the demographics of students taking ECS reflected the demographics of the district as a whole [5], there was an uneven distribution of schools that were offering the course, due to the voluntary nature of participation. The enactment of the graduation policy had an immediate effect. In the first year of the policy implementation, the number of students taking ECS increased to just over 8000. However, the shift from computer science as an elective course to a graduation requirement changed the nature of who is taking ECS. A significant number of the students are taking ECS because it is a requirement, which could influence their motivation to take additional computer science coursework.

The graduation requirement has also changed the nature of who is teaching ECS. Prior to the graduation requirement, the majority of the ECS teachers had a background or certification in computer science. Starting in the first year of the graduation requirement implementation, the majority of the teachers had a background in other STEM disciplines, such as math or science [6]. While the ECS PD program is designed to accommodate teachers with little computer science background, prior research has not examined the extent to which teachers' backgrounds is related to student success in the ECS course. Our research is guided by the following research questions:

1) Is the rate at which ECS students take additional CS coursework after the graduation requirement consistent with the rate prior to the graduation requirement?

2) To what extent does the teacher's level of CS background 
correlate with the rate at which students take additional coursework?

\section{Methods/Data}

\section{A. CPS District Data}

Through a data sharing agreement with the district, we were provided with data about the students in this sample. The district provided the certification area and experience teaching ECS for teachers who taught ECS, along with students' cumulative GPA for the year they completed ECS, their ECS course grade, grade level, and demographic information about race, gender, and designation as special education, English Language Learner, and/or free or reduced lunch participation. The district also provided information about any subsequent computer science courses students completed in the years after completing ECS. This last variable will be the dependent variable for the study to provide evidence on whether future course taking for students who took ECS as a requirement is consistent with students who took ECS as an elective.

\section{B. Population}

This study took place during the 2016-17 through 201819 school years. Since the freshman class who entered CPS during the 2016-17 school was the first class to whom the requirement applied, the study focused on students who entered as freshman in 2016-17 or 2017-18 and examined whether they took another CS class in subsequent years. The population was further narrowed to include only those students at neighborhood schools that offered additional CS coursework. In addition, students participating in Career and Technical Education or the International Baccalaureate program were excluded since those students were eligible to waive the requirement. There were 2105 students in the sample. Of the original 2105 observations, 546 were omitted due to missing data. Observations with any missing data were removed and no imputation was performed, leaving 1559 observations for the analysis. Each observation was a unique student who each had one of 30 unique ECS teachers.

\section{RESULTS}

The overall rate at which students took additional CS coursework during the study period was $13 \%$. Since students were nested within classes, we conducted multilevel linear modeling on the probability of taking another CS course using $\mathrm{R}$ version 3.6 .2 and version $1.1-21$ of the lme4 package. A Generalized Linear Mixed-Effects model was fit using a binomial family probability distribution and a logit link function to predict the log odds of a student taking more than one computer science course. Fixed effects at the student and teacher level with random intercepts by teacher were measured. The results are in Table I. The statistically significant variables are bolded. All of the teacher level fixed effects were insignificant, with student gender and cumulative GPA being the only significant student fixed effects. Students who were female were about half as likely to take a second computer science course as males. Students with a higher GPA were
TABLE I

Results of Logistic Regression Predicting Whether Students TOOK ANother Computer SCIENCE COURSE

\begin{tabular}{|c|c|}
\hline Independent Variables & Probability of Taking More CS \\
\hline Constant & $\mathbf{- 1 . 0 4 *}$ \\
\hline Teacher Characteristics & -0.73 \\
\hline CS Background & 0.13 \\
\hline ECS Teaching Experience & \\
\hline Achievement & $\mathbf{0 . 3 3} *$ \\
\hline GPA & 0.14 \\
\hline Course Grade & \\
\hline Race & -0.08 \\
\hline African American & -0.29 \\
\hline Hispanic & $\mathbf{- 0 . 5 8 * * *}$ \\
\hline Female & -0.44 \\
\hline Special Population & -0.32 \\
\hline Special Education & -0.28 \\
\hline ELL & 0.13 \\
\hline Free or Reduced Lunch & \\
\hline Attendance & \\
\hline
\end{tabular}

Significance Levels: $0.05=* ; 0.01=* * ; 0.001=* * *$

about $7 \%$ more likely to take additional CS coursework for each 1 point their GPA was above average.

\section{CONClusions}

The results indicate that students subject to the graduation requirement took additional CS coursework at a much lower rate (13\%) than students who took ECS as an elective (43\%) [4]. However, the total number of students taking ECS has significantly increased, so the total number of students taking additional CS will also continue to increase. As ECS continues to expand in CPS, an increasing number of teachers will be teaching ECS with limited CS background. The background of the teacher did not influence the extent to which students took additional coursework. The results of this research will be directly applicable to informing efforts to use ECS as a means to broaden participation in computer science.

\section{REFERENCES}

[1] L. Dettori, R. I. Greenberg, S. McGee, D. Reed, B. Wilkerson, and D. Yanek, "CS as a graduation requirement: Catalyst for systemic change," in SIGCSE '18. Association for Computing Machinery, Feb. 2018, pp. 406-407, Baltimore, MD. https://doi.org/10.1145/3159450.3159646.

[2] J. Goode, J. Margolis, and G. Chapman, "Curriculum is not enough: The educational theory and research foundation of the exploring computer science professional development model," in SIGCSE '14. Association for Computing Machinery, 2014, pp. 493-498.

[3] D. Reed, B. Wilkerson, D. Yanek, L. Dettori, and J. Solin, "How Exploring Computer Science (ECS) came to Chicago," ACM Inroads, vol. 6, no. 3, pp. 75-77, Sep. 2015.

[4] S. McGee, R. McGee-Tekula, J. Duck, L. Dettori, D. Yanek, A. Rasmussen, R. I. Greenberg, and D. F. Reed, "Does Exploring Computer Science increase computer science enrollment?" in American Educational Research Association (AERA) Annual Meeting, Apr. 2018, New York, NY. https://www.academia.edu/36446926.

[5] S. McGee, R. McGee-Tekula, L. Dettori, A. M. Rasmussen, and R. I. Greenberg, "Research methods for reaching urban students from groups underrepresented in STEM disciplines," in Navigating Challenges in Qualitative Educational Research: Research, Interrupted, 1st ed., T. Ruecker and V. Svihla, Eds. Routledge, 2019, ch. 3, pp. 26-38.

[6] S. McGee, L. Dettori, R. I. Greenberg, A. M. Rasmussen, D. F. Reed, and D. Yanek, "The changing profile of ECS teachers," in SIGCSE '20. Association for Computing Machinery, Mar. 2020, Portland, OR. 